\title{
Description and Regulation of Drilling Completion Fluid Cake Structure
}

\author{
Xue Liu, Dong Ma, Pengfei Mu, Zhanhua Zhang, Junbo Yao \\ CNOOC Tianjin Company, Tianjin, China \\ Email: liuxue9@cnooc.com.cn
}

How to cite this paper: Liu, X., Ma, D., $\mathrm{Mu}$, P.F., Zhang, Z.H. and Yao, J.B. (2018) Description and Regulation of Drilling Completion Fluid Cake Structure. Open Journal of Yangtze Gas and Oil, 3, 293-308. https://doi.org/10.4236/ojogas.2018.34025

Received: June 1, 2017

Accepted: October 26, 2018

Published: October 29, 2018

Copyright $\odot 2018$ by authors and Scientific Research Publishing Inc. This work is licensed under the Creative Commons Attribution International License (CC BY 4.0).

http://creativecommons.org/licenses/by/4.0/

\begin{abstract}
In the process of oil and gas well drilling and completion, under the action of positive pressure gradient or self-absorption, drilling and completion fluid solid phase particles block the reservoir pore and form the filter cake. The filter cake plays a vital role in reservoir protection, and is closely related to the oil and gas well productivity from cake formation to remove. The filter cake is always expected to be thin, tough, with low permeability and easy to remove. Many scholars made a lot of research from the filter cake layer structure, space truss structure, pore structure and the structure of fractal structure of filter cake. However, the researches on the structure of the filter cake are mainly conducted qualitatively at home and abroad, while the quantitative research progress is slow. At the same time, the research on the relationship between the filter cake structure and its performance is also relatively weak. In recent years, with the wide application of horizontal wells, it has called widespread attention on how to effectively remove filter cake in order to improve the oil and gas well production capacity at home and abroad. The widely-used filter cake removal technology mainly includes natural clear, mechanical removal, chemical removal and biological removal technology currently. Among them, the biological removal technology is developed in recent years as a new type of filter cake removal technology. With the further development of mud cake removal technology and downhole filter cake removing circumstance with increasing complexity, a single filter cake removal technology cannot completely meet the requirements. The filter cake removal technology is developing in the direction of the composite to clear, in order to obtain ideal filter cake removal effect.
\end{abstract}

\section{Keywords}

Drilling Completion Fluid, Reservoir Damage, Cake Structure, Mud Cake Removal 


\section{Introduction}

In the whole process of the exploration and development of oil and gas wells, the well fluid (such as drilling completion fluid, fracturing fluid and injected water, etc.) is under the action of pressure difference or self-priming, through reservoir porosity into the reservoir. After a period of time, the solid phase particles blocking the pore formed filter cake. Since then, and they can only filtrate invasion of reservoir. The filter cake which we usually mention generally refers to the drilling completion fluid filter cake, which is widespread in the process of oil and gas wells in the drilling and completion, and the damage to the reservoir and that has important effects on the oil and gas well production capacity. The existence of the filter cake will cause damage to the reservoir, for example, to reduce the reservoir permeability, but also can effectively filter cake used to achieve the goal of reservoir protection. The thin, flexible and low permeable filter cake formed on the wall can reduce and prevent the damage of solid phase invasion and water phase trap, and improve the ability of the porosity logging recognition of tight sandstone. It also could stop work fluid pressure transmit to the formation, and stable the sidewall formation pore pressure to the original state pore pressure, prevent the extension of reservoir fracture (weaken or eliminate the stress sensitivity of reservoir). At the same time, in the drilling completion homework, the differential form of filter cake making particles near the wellbore reservoir effective stress increases gradually, enhancing the ability of resistance to tensile rupture rock, and thus enhancing the fracture pressure of reservoir near the wall and the bearing capacity, preventing borehole wall instability and reservoir leakage [1] [2] [3].

Filter cake is a complex of porous media. The pore size, shape and distribution of fluid motion play an important role. So the geometrical porous structure of filter cake is one of the important factors, which also can decide the filter features [4]. The filter cake quality is directly related to the reservoir damage degree, borehole wall stability and borehole quality [5]. In order to reduce the down hole accidents, drilling completion fluid leakage, and reservoir damage degree, the filter cake is always expected to be thin and tough, with low permeability [6]. In 7 subsequent production construction, it has received extensive attention on how to effectively remove the filter cake in order to improve the oil and gas well production capacity. The filter cake, removing incomplete or purify uneven wall, not only can reduce capacity, but also is easy to cause the well loss at the bottom and liquid phase in the course of production of the dash [7]. Therefore, it is very important to study the microstructure, performance of the filter cake, figure out how to effectively clean the tight filter cake and recover the permeability of reservoir.

\section{Filter Cake Formation}

In the process of drilling completion of oil and gas well, the filter cake is formed by solid phase of the well completion fluid plugging the pores of the reservoir, 
due to the pressure difference and in-drawing effect. The filter cake is divided into the inner filter cake and the outer filter cake (see Figure 1), which can be formed either in static filtration or during dynamic filtration.

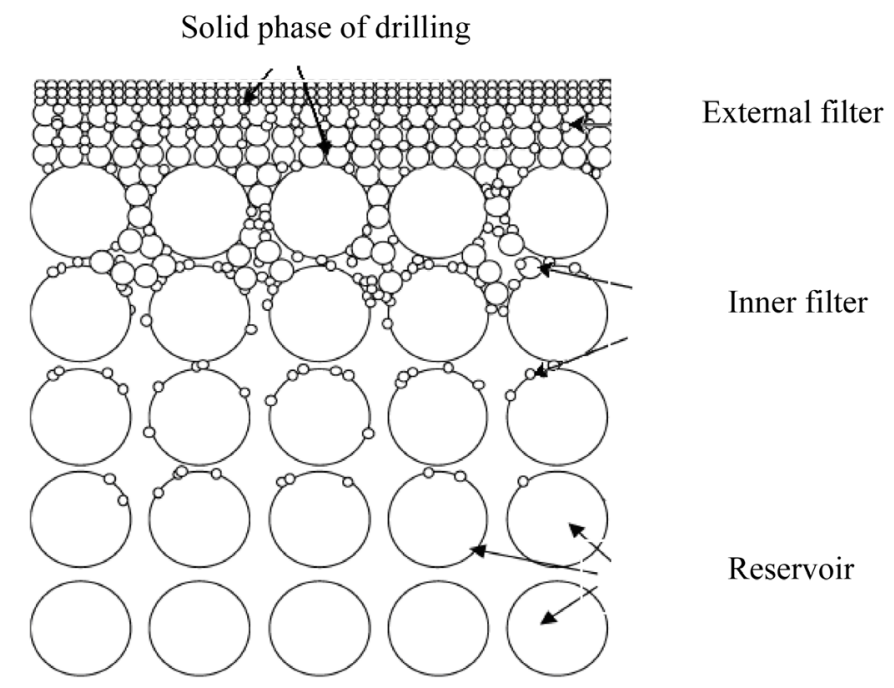

Figure 1. Internal and external filter cake schematic (according to Ajay, Suri, 2004 [8]).

During the drilling and completion of oil and gas wells, solid filter particles are formed by plugging the pores of the drilling and completion fluid with positive pressure or imbibition. The cake is divided into inner and outer filter cake (Figure 1), which can be formed in the static filtration time, or in the dynamic filtration time.

During the static filtration process, the formation of cake is mainly caused by the gravitational precipitation of particles and the force between particles. In the process of dynamic filtration, the formation of cake is mainly controlled by the acting force acting on the drilling fluid and the pore pressure of the reservoir. There is a direct relationship between rheology and shear rate distribution. Drilling fluid particle velocity dynamic filter cake formation and drilling fluid in large and small particles can be deposited at the same time to the bottom of the cake, but only small particles can be deposited into the upper part of the filter cake; when the minimum particle deposition to drilling fluid on the cake, the cake thickness will reach a dynamic balance, so that the filtration rate can reach a dynamic balance; at the same time, the formation of the dynamic filter cake has a minimum balance pressure and permeability of the cores, below which, the filter cake can form [9] [10]. In the shielding temporary plugging technology, in order to form the low permeability filter cake, which can effectively seal the reservoir, the matching relationship between the temporary plugging particles and the pore throat size (crack width), has been the focus of the study.

For the pore type formation, according to the blocking characteristics of drilling completion fluid, theory of the third bridge, two-thirds of Bridges was proposed by researchers, which is based on single grain of pore blocking model, double (grain) bridging plug model [11] [12]. Luo Xiangdong explored the 
bridging particle and filling particle filling pattern, where the diameter of bridging particles and the pore average diameter of optimal match relations for $2 / 3$, and the concentration should not be less than $3 \%$, and the filler particle concentration should not be less than $2 \%-3 \%$ [13].

Bernt emphasized that in order to obtain stable bridge, the largest temporary plugging particle diameter should not be less than the width of crack [14]. Jiang Haijun pointed out the stability of the bridge can be achieved when the diameter of bridging particles and the width of crack match relationship between (0.5 1):1, and bridging particle concentration is not less than $3 \%$ [15].

\section{Structure Description of Filter Cake}

The cake is a porous medium by many uneven sized particles, where small particles are embedded in large particles. The microstructure mainly refers to skeleton particles and the cake pore geometry, size and as well as its distribution.

The study of the structure of filter cake belongs to the field of geometry. Its particle shape and the porous network structure inside the filter cake can't be described by traditional geometry. The analysis of the particle morphology and the internal structure of the filter cake are of great significance to the further study of the formation mechanism and characteristics of the cake [16]. People have always tried to find an effective way to study the structure of filter cake. In recent years, the test to internal structure of filter cake become possible by the development of scanning electron microscopy and the automatic image processing technology. These technologies make the porosity and pore size distribution more comprehensive and accurate. The results of scanning electron microscope and image analyzer show that the results of porosity and pore size distribution are more comprehensive and accurate than those obtained by indirect test [17].

Many domestic and foreign scholars have done a lot of research on the structure of filter cake, starting from the layered structure, grid structure, pore structure and fractal structure and so on, contributing to a more in-depth understanding of the cake structure (Table 1).

Table 1. Structure description of filter cake.

\begin{tabular}{|c|c|c|}
\hline Structure description & Research methods & Findings \\
\hline Layered structure & $\begin{array}{l}\text { Analyzed the change } \\
\text { of mechanical } \\
\text { characteristics for cakes }\end{array}$ & $\begin{array}{l}\text { The physical model of the } \\
\text { layered structure of the } \\
\text { filter cake is established }\end{array}$ \\
\hline grid structure & Double layer theory & $\begin{array}{l}\text { The structure of filter cake is } \\
\text { a kind of space grid structure }\end{array}$ \\
\hline pore structure & $\begin{array}{l}\text { Freeze drying technique and } \\
\text { scanning electron microscope }\end{array}$ & $\begin{array}{l}\text { The filter cake shows a } \\
\text { honeycomb pore structure }\end{array}$ \\
\hline Structure fractal & Fractal theory & $\begin{array}{c}\text { The cake structure is a piecewise } \\
\text { Sierprinski fractal }\end{array}$ \\
\hline
\end{tabular}




\subsection{Layered Structure of Filter Cake}

Based on the intensive study of factors, which affects the cake strength, thickness and elastic plastic on the cake structure, Zhou fengsha etc. established a physical model and a mathematical model of outer filtering [18]. By analyzing mechanical characteristics during the process of the outer filter cake failure under axial pressure, according to the strength and compactness, the outer filter cake is divided into virtual mud cake, compressible layer cake, dense layer cake and tight filter cake (there are no layers in fact and mud cake characteristics change continuously). On this basis, layered structure physical model of the outer filter cake was established, physical meanings and the difference between layers were interpreted [19] (Figure 2).

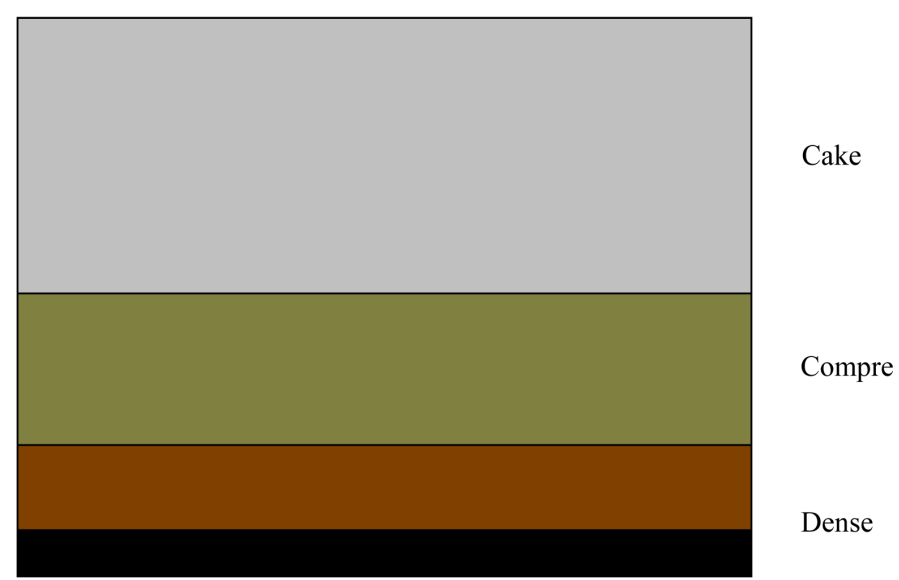

Figure 2. Cake layered structure physical model (according to Zhou fengsha, 2003).

\subsection{Pore Structure of Filter Cake}

For the measurement of the porosity of filter cake, the local porosity distribution in the cake during constant pressure filtration can be directly measured by means of electrical measurement [20]. The results show that during constant pressure filtration, the porosity of any position in the cake decreases with the increase of time, and is asymptotically constant according to the difference of filtration pressure.

Chenevert M E and Zhang Da Ming etc. studied the microstructure of the filter cake by freeze drying and scanning electron microscopy [21] [22]. The results show that the mud and polymer drilling fluid filter cake honeycomb pore structure (Figure 3), pore size and distribution of honeycomb with drilling fluid ratio varies, barite, ultrafine $\mathrm{CaCO}_{3}$ and sulfonated asphalt can play a blocking filter cake pore and reduce the filtration. The pore size of the cake decreases when the solid pressure in the filter cake increases. The pore size of the filter cake depends on the additives in the drilling and completion fluid, not on the concentration of bentonite in the drilling and completion fluid. The structure of filter cake is also affected by the circulation of drilling and completion fluid. That is, the structure of the static filter cake and the dynamic filter cake are different. 


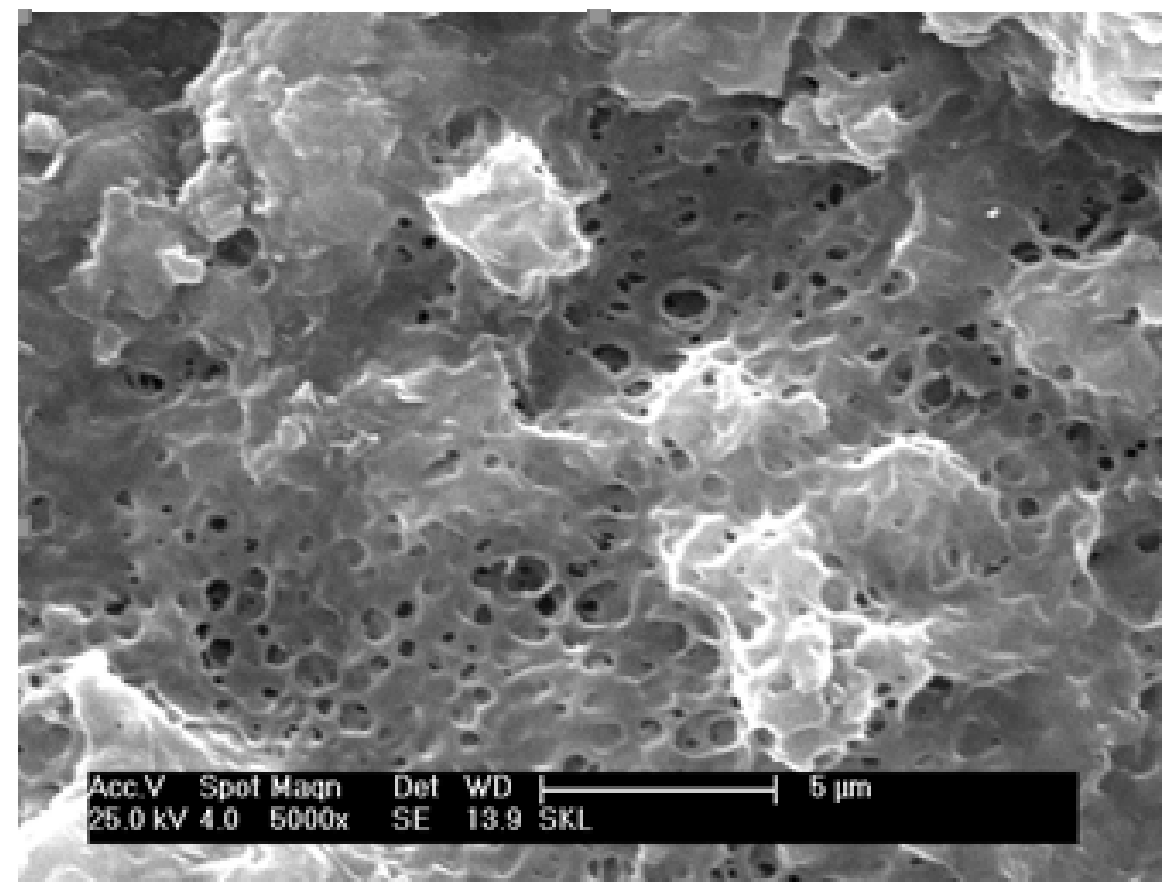

Figure 3. SEM pictures of filter cake $(\times 5000)$ (Chenevert and John, 1991).

\subsection{Fractal of Filter Cake Structure}

Xu Xinyang used SM505 scanning electron microscope and IDASKAT380 automatic image analyzer and other modern testing methods, testing the structure of filter cake formed under different conditions, and then from the fractal theory, the fractal characteristics of [23] filter cake structure. The results show that the cake structure is a piecewise Sierprinski fractal, and the fractal structure can be used to describe the cake structure. The size of the fractal dimension reflects the distribution of the pore size of the filter cake and the filtration of the cake. The size of fractal dimension is related to material properties and operation factors. The larger the specific surface area of the material is, the smaller the filtration pressure difference is, and the larger the fractal dimension is.

Based on the scanning electron microscope (SEM) and the image analysis of the filter cake, the fractal dimension [24] of the pore section boundaries of various filter cakes can be measured and determined by the island method. The fractal dimension of the pore boundary of the filter cake can reflect the microstructure of the cake. The bigger the fractal dimension is, the more irregular the pore size of the cake is, the rougher the pore wall is and the larger the surface area is.

According to the Sierpinski fractal model, the scaling relation of the pore size fractal dimension of the filter cake is established [25]:

$$
B(\geq r)=C_{0}\left(\pi r^{2}\right)^{2-D_{s}}
$$

$B(\geq r)$ - Remove the remaining holes equivalent radius of not less than $\mathrm{R}$ after the filter cake

$C_{0}$-Proportionality constant 


\section{$r$-Characteristic scale}

$D_{\text {s }}$ - The pore size similarity dimension of filter cake is also called the fractal dimension of cake size, $1<D_{s}<2$

Based on the fractal theory, the mid pore diameter $\left(D_{50}\right)$ and the fractal dimension ( $D s)$ represent the pore size and the distribution of pore size respectively, the characteristic parameters represent the filter cake pore structure [25]. The $C$ value comprehensively reflects the pore size and distribution of the cake. The larger the $C$ value is, the larger the pore size of the filter cake is, the narrower the pore size distribution is, which is beneficial for the filtrate to pass through.

\subsection{Relationship between Structure and Properties of Filter Cake}

Li Yidan with filter paper and rock slices of simple water-based drilling fluid in static and dynamic conditions of filtration, observed the cake structure characterized by low temperature scanning electron microscope, on the basis of the relationship between the two [25]. The results show that the outer structure of filter cake formed by filter paper and rock slices are similar; polymer chain invaded the rock deeper than that of the clay particles. The filtrate loss of drilling and completion fluid of dynamic process is larger than that of static filtration. The grid structure of the filter cake is more regular; and with the increase of the polymer, the effects of shear rate of drilling completion fluid filter cake structure become smaller.

The dynamic filtration rate of drilling and completion fluid under different conditions was measured by using SW - II core dynamic damage instrument. Scanning electron microscope and particle size analysis of dynamic filter cake [26] were carried out. The results show that the permeability of the filter cake is mainly determined by the size and distribution of the particle size of the solid phase, and decreases with the increase of the pressure difference, and increases with the increase of shear rate or permeability. The results of SEM analysis show that the permeability of the filter cake is mainly determined by the size and distribution of the particles in solid phase. Permeability decreases with the increase of the pressure difference, and increases with the increase of shear rate or media permeability. The results of SEM analysis also show that the size of solid particles is finer and denser in high pressure difference than that in low high pressure under the same shear rate; the size of solid particles is coarser and more porous in high shear rate than that of low shear rate under the same pressure difference. With the increase of permeability, the solid particles in the filter cake become coarser. Grain size analysis shows that with the decrease of pressure, shear rate or permeability of medium, the average particle size of solid particles in filter cake increases, and the content of coarse particles increases.

Liu Peng et al. [27] through the analysis of the particle size of the filter cake, discussed the effects of particle density, particle shape and particle size distribution and particle adhesion on the cake properties. It is believed that the finer of the particles in the filter cake, the bigger the specific surface area is, the greater the resistance is. The closer the particle diameter is,, the more uniform the dis- 
tribution is, the bigger the pore space between the particles in the accumulation is, so that the filtration resistance is reduced. The denser the particles is, the bigger the settling velocity is, the faster the formation of cake is, and the tighter the cake is. The adhesion between the particles hinder the particle movement; under the same effective pressure, the greater the adhesion, the more difficult of the particles movement and the more difficult of filter cake compression will be, resulting in high porosity.

\section{Study on Cake Cleaning Technology}

In the drilling process, the formation of the outer filter cake is the drilling fluid filtrate to filter the reservoir and solid invasion is one of the effective methods to the lowest, especially for the completion of the long open holes and gravel without horizontal and deviated wells in any perforation completion period of filling. The quality of the filter plays an important role. However, drilling fluid formed on the wall of the dense filter cake, although the invasion of filtrate and solid particles decreased, which will seriously affect the productivity of oil and gas wells in the subsequent production process. To completely remove the dense filter cake adhering to the wall is difficult, especially in low permeability reservoir. In addition, deep exploration and multi objective layer of oil and gas exploration wells in the middle test, completion test and drilling operations, inevitably result in damage and repeated formation of drilling fluid filter cake. In addition, during the middle test, completion test and drilling operations of deep exploration wells and multi-target exploration wells inevitably result in damage and repeated formation of drilling fluid filter cake. The repeated formation of drilling and completion fluid filter cake on the base block and fracture, the temporary plugging rate and strength are improved. However because the filter cake continued to promote into deep reservoir, the difficulty of removing the cake greatly increased. The filter cake removal technology is mainly used in horizontal wells. Researches show that the filter cake removal technology widely used at home and abroad includes natural removal, mechanical removal, chemical removal and biological removal (Table 2).

Table 2. Description of cake cleaning technology.

\begin{tabular}{|c|c|c|c|}
\hline $\begin{array}{l}\text { Cake removal } \\
\text { technology }\end{array}$ & Removal method & Characteristics & Scope of application \\
\hline Natural removal & Pressure drop & $\begin{array}{l}\text { Easy to apply and the cake } \\
\text { removal efficiency is low }\end{array}$ & $\begin{array}{l}\text { Mainly in the open hole } \\
\text { completion section }\end{array}$ \\
\hline $\begin{array}{l}\text { Mechanically } \\
\text { removal }\end{array}$ & $\begin{array}{l}\text { Jets: erosion, } \\
\text { cutting dissolve }\end{array}$ & $\begin{array}{l}\text { Removal effect is better } \\
\text { in near wellbore area }\end{array}$ & $\begin{array}{l}\text { Mainly in open hole } \\
\text { completion section }\end{array}$ \\
\hline Chemical removal & $\begin{array}{l}\text { Dissolves soluble } \\
\text { substances and } \\
\text { degrade polymer }\end{array}$ & $\begin{array}{l}\text { Removal effect is better but } \\
\text { it will cause damage to the } \\
\text { reservoir and the pipe string }\end{array}$ & $\begin{array}{l}\text { Cake containing } \\
\text { acid soluble } \\
\text { substance and polymer }\end{array}$ \\
\hline Biological removal & Degrade polymer & $\begin{array}{l}\text { Removal effect is better } \\
\text { and have little } \\
\text { damage to reservoir }\end{array}$ & $\begin{array}{c}\text { Cake } \\
\text { containing polymer }\end{array}$ \\
\hline
\end{tabular}




\subsection{Natural Removal Techniques}

The natural removal of the cake is commonly known as natural flow back, removal the cake by pressure drop. Natural removal technology is the most basic removal technique of filter cake, but the selection of pressure drop is restricted by many production factors, so the removal efficiency is low in field application. However, for horizontal wells that can't be used for perforation completion, the natural flow back method is superior to the chemical removal method. The particles released when the cake is broken may enter the reservoir again, causing further damage when using the chemical removal technology.

Zain Z. M. et al. [28] pointed out that the natural flow back of cake is mainly affected by rock permeability, drilling fluid performance, flow back rate and pressure difference. The key to removal cake during flow back is dependent on the permeability and mechanical properties of the cake itself, irrespective of the initial flow pressure. If the filter cake has low permeability and high yield strength, then the pressure drop on the cake is high, and the cake may be completely stripped and removed from the rock surface. The removal of the inner filter cake is more difficult than the external filter cake, and the further research is needed.

Experimental studies were carried out by Liu Jing et al. [29] on the fracture pore reservoirs shielding temporary plugging technique. They pointed out that when the fracture width of the rock well match the peak of the particle size distribution of the drilling \& completion fluid, temporary plugging and flow back effect works well. They pointed out that there is a breakthrough pressure Pd. Only when the flow back pressure is greater than Pd, the cake can fall off, and the fluid flow back, the natural flow back effect worked.

Ding, [30] studied a simplified numerical model for simulating the natural removal of cake form in oil based drilling and completion fluids under different production pressures. The results show that removal outside cake is more important than the inside cake. The outside cake is formed in the complex condition, once the pressure drops improperly, residual part of the filter cake will remain in the wall permanently, seriously affecting the subsequent production. However, in this model, the effects of geological mechanics and permeability anisotropy are not considered, and this model needs further studies.

\subsection{Mechanical Removal Techniques}

Mechanical removal is mainly jet, and the jet can be divided into hydraulic jet and acid jet. The brine or acid liquid is ejected from the nozzle hole at high pressure and impact the surface of the wellbore at high speed. This cake removal method is carried out through erosion, cutting and dissolving. The efficiency of jet removal is affected by the distance between nozzle and wellbore, liquid viscosity, jet velocity, duration, jet tool rotating speed and other factors. Generally speaking, when the jet time is long and the jet velocity is higher, the removal of cake and the effect of reservoir reconstruction are better.

Mikhailovich [31] compared the removal efficiency of water jet and jet acid, 
the results showed that acid jet is more sensitive to the jet velocity and jet duration; the average core permeability recovery of acid is much larger than water jet. But in field experiments, the acid jet and hydraulic jet are of little difference. Considering the process and cost, the comprehensive effect of hydraulic jet is better than that of acid jet.

Adinathan studied the removal of near wellbore damage by ultrasonic technique in experiment The results show that the main mechanism of ultrasonic removal is the effect of acoustic flow and acoustic cavitation. The core permeability recovered to a certain extent by ultrasonic with different frequencies and intensities, but its effective depth is about 2.5 inches, and has no effect on the deeper part. The ultrasonic efficiency depends on the ultrasonic frequency, power, duration, and the coupling relationship between the ultrasonic and the treated material. This study provides a new idea for the removal of cake.

\subsection{Chemical Removal Technique}

The chemical removal technology is one of the most widely used cake removal technologies in field application. The main removal solution includes various oxidants, acids and chelating agents.

1) Cake removal by oxidant

Oxidants are highly active substances that remove polymers, and their activity increases with increasing $\mathrm{PH}$ and temperature. Ideally, the oxidant reacts with the major bond and site of the polymer chain and degrades the polymer into a basic sugar unit.

Wang Fuhua [32] took advantage of new experimental techniques for reservoir protection evaluation with combined fractures, and evaluated the plugging removal effects of several oxidants. The results show that the removal effect of oxidized solution plugging agent effect is obviously better than that of non-oxidized plugging agent. $\mathrm{ClO}_{2}$ has strong oxidation, so it has the best removal effect; its success rate is more than $100 \%$, followed by ammonium per sulfate and hydrogen peroxide.

Ronny, Genaro and others conducted experiments to investigate the removal efficiency of sodium hypochlorite. The results show that the oxidant, although does not reach to $100 \%$ to remove the filter cake in the polymer, it can cut through the polymer chain to achieve the effect of viscosity reduction, and with oxidant treatment, the cake is divided into discrete parts, easy to remove in reservoir fluid flow. In this process, oxidizing agents can either contact parts with the polymer chain or many underground substances and react, therefore, after oxidant treatment, the filter cake still keep part of polymer degradation products, a lot of non-degradable polymers as well as all of the calcium carbonate granules; in addition, oxidant are some damage to reservoir and string.

2) Cake removal by acid

There are two kinds of acid used in cake removal process: chemical acid and organic acid. 
Chemical acids can dissolve the acid soluble cuttings and calcium carbonate in the filter cakes, and strong acids can degrade certain polymers. The conventional method is through cleaning naked wellbore, but the practice shows that only use chemical acid the removal is not complete, because this method has the following problems: a) acid can only remove skeleton particles in the filter cake such as superfine calcium carbonate, but can't degrade the polymer or can only degrade some polymer; b) the filter cake in the polymer may wrap part of acid soluble solids, decreasing the rate of reaction; c) the reaction part of acid and the reaction rate is not controllable, easy to form local acid dissolved pores, causing "seduced damage" to formation; d) the acid can react with a variety of substances and poorly targeted, so it is consuming. e) With the increase of temperature, the activity of acid becomes intensive, and the acid corrosion and residual acid treatment problem becomes more serious. In addition, the removal of cake by chemical acid will cause certain damage to the downhole pipe string.

In order to solve the problem of removing the cake by chemical acid, a new kind of cake removal system cuss has been developed recently. The main component of the system for organic acids, combines the advantages of acidification and oxidation. It can dissolve acid soluble bridging particles, at the same time has the characteristics of strong oxidant, it can degrade the polymer molecules and make the filter cake lose bridging and adhesion effect and transfer the filter cake from dense, tough to loose and broken, remove the filter cake efficiently.

Because the drilling fluid has the ability to maintain the stability of the conventional polymer under high temperature, in recent years it has been using the drilling deep wells abroad. $\mathrm{Mn}_{3} \mathrm{O}_{4}$ has been used as water-based drilling fluid weighting materials. The two new types of drilling and completion fluids cannot be removed by conventional acid. The experimental results show that the removal of organic acids is better.

3) Cake removal by in situ acid system

Situ acid system mainly includes: front acid, the role of which is hydrolysis to organic acids; an inorganic catalyst to catalyze the hydrolysis of esters; an enzyme or oxidizing agent to degrade polymer; a nonionic surfactant, viscosity and surface tension. The system can control the rate of acid production and achieve the goal of removing calcium carbonate and polymer in the cake in one step.

Nasr-el-din [33] studied the removal effect of in situ acid system in gas well with the improved high temperature and high pressure loss tester. The results showed that acid concentration was better in $6 \%-10 \%$, and higher concentration might lead to organic acid calcium. This system has low surface tension, easy flow back, scavenging effect and other advantages, which can degrade cake form by $\mathrm{KCl}$, polymer and drilling fluid, but at a higher temperature (about $104^{\circ} \mathrm{C}$ ) of this system will occur phase separation, affecting filter cake removal effect.

In order to make the acid system still play good removal effect on the cake at high temperature, Al-Otaibi M. B. et al. [34] was optimized from several esters 
that include acetate, lactate ester and lactic acid esters. Through optimization, lactic acid ester was used as prepositional esters. It is stronger than acetic acid, and the production rate at high temperature is faster than formic acid. The $\mathrm{PH}$ value of lactic acid buffer solution is about 4 , which has great catalytic effect at a high temperature hydrolysis of starch polymer in the filter cake. This can ensure the speed and strength of acid, and can improve the removal efficiency of the cake.

4) Cake removal by complex

After a lot of field applications, it is found that the removal of cake is not very good when the oxidant, acid or chelating agent is used alone. In recent years, people have begun to consider the combination of a variety of cake removal methods, so as to achieve an ideal filter cake removal effect.

The oxidizing agent can be used in conjunction with the acid to remove the cake. Because the oxidant can oxidize $\mathrm{HCl}$ to produce a poisonous $\mathrm{cl}_{2}$, the acid and oxidant are to be used step by step. In recent years, a new kind of filter cake removal system including oxidant and organic acid has been developed by using strong buffer organic acid and oxidant. The system is based on buffered carboxylic acid solution (PXCA). A large number of experimental results show that PXCA treatment solution has the advantages of high cleaning efficiency, short processing time and simple usage. When the same cake cleaning effect was achieved, the soaking time of PXCA treatment liquid was $4 \mathrm{~h}$, while the immersion time of hydrochloric acid or hypochlorite alone was $12 \mathrm{~h}$.

For horizontal wells with screen completion, in order to effectively remove oil based drilling fluid filter cake from the reservoir and screen plugging, an emulsion oil based drilling fluid filter cake removal KFC has been developed. It is a relatively stable oil in water emulsion. Study route map of KFC is: decomposing skeleton particles in the filter cake with acid under the strong penetrating agent, and the filter cake loosening; organic solvent to dissolve asphalt filtration control agent; then filter cake treated with high efficiency cleaning permeable agent; chelating agent to prevent metal ion precipitation, at the same time, the addition of clay stabilizer to prevent filter cake removal liquid into the reservoir to cause clay swelling damage.

\subsection{Biological Removal Technique}

The development of biotechnology has made it possible to remove polymer damage by new enzyme breaker, and it also proves that the effect of oil production in oil and gas wells is remarkable. Biological enzyme is a kind of special macromolecule protein produced by biological organism. It is a catalyst to increase the rate of chemical reaction. It can be used as a gelling agent to degrade polymer. In the process of degradation, the biological enzyme can keep the structure unchanged, and has the characteristics of never dying away and activity unchanged. It is found that the enzyme can degrade the polymer in drilling fluid, and let the calcium carbonate granules down from polymer, effectively 
remove the filter cake, which can better restore the reservoir permeability.

The biological enzyme in the degradation of the polymer follows the "key to lock" principle, therefore, according to the particularity of the polymer chain, using a unique enzyme, namely SEB (specific enzyme breaker). After adding SEB to the drilling and completion fluid to remove some of the polymer in the cake, the remaining cake still has the ability to decrease permeability. At the same time, because the enzyme can keep stability and activity for a long time, it can react with the remaining polymer in order to remove repeatedly. The core flow test showed that acid treatment after SEB was very effective.

In order to enhance the flow back ability and suspension ability of biological enzyme treatment fluid, Nasr-El-Din H. A. et al. [35] pointed out a kind of viscoelastic surfactant, and used it in combination with biological enzyme. Adding viscoelastic surfactant, not only improved the solution viscosity and filtrate loss reduction, enhanced suspension capacity, and decreased surface tension of enzyme and improved the degradation rate of polymer and flow back ability.

In recent years, with the development of enzyme degrading polymer technology, new enzyme unplugging drilling completion fluid has also been applied. Enzyme unplugging drilling fluid has the biodegradation characteristics, and degrade the temporary plugging materials which invaded reservoir and adhesion on the wall of well in the process of drilling into carbon dioxide and water. After completion without the use of conventional plugging technology, the filter cake can get rid of wellbore under the biological enzyme automatic degradation. The system mainly comprises cellulose, modified starch, bio polymer treatment agents, which can guarantee the smooth passage of reservoir fluid in the drilling process, recover the permeability of reservoir, and is environmentally and undamaged to reservoir.

\section{Conclusions and Recommendations}

Cake layer structure is divided into pseudo filter cake, compressible layer cake, dense layer filter cake and ultra-dense layer filter cake from top to bottom. The cake structure is under influence of pressure difference, shear rate, medium permeability and the size and distribution of solid particles in drilling and completion fluid. Electron microscope scanning shows that drilling fluid filter cake has structure of honeycomb; the study of clay particle interaction by electric double layer theory shows that the filter cake structure is a space grid structure; and the fractal study of the filter cake microstructure shows the filter cake structure is a segmented Sierprinski fractal. Widely used filter cake removal technologies mainly include natural removal, mechanical removal chemical removal and biological removal technology, etc. In field applications, corresponding removal methods should be designed according to specific conditions.

At present, the following several aspects need more research to the structure of filter cake. With the further development of the filter cake removal technology, the down hole filter cake removal situation is becoming increasingly com- 
plex. A single filter cake removal technology has been unable to fully meet the requirements. Composite filter cake removal technology is a new direction, in order to effectively remove the cake and restore the reservoir permeability. At the same time, the study of the structure of the filter cake mainly stays in the qualitative research, which is relatively weak. The study of the cake structure of the horizontal well needs to be strengthened.

\section{Conflicts of Interest}

The authors declare no conflicts of interest regarding the publication of this paper.

\section{References}

[1] Luo, X.D., Bo, X.L., Wei, Z.M., et al. (1995) Plugging the Fractured Drain in Horizontal Well with Shielding Temporary Plugging Technology. Oil Drilling and Production Technology, 17, 28-31.

[2] Liu, J.J., Kang, Y.L. and Wang, Y.Z. (2007) Theory and Technology Progress of Extended Drilling Fluid Safety Density Window. Drilling Fluid and Completion Fluid, 24, 69-73.

[3] Yu, L.J., Kang, Y.L. and Chen, Y.J., et al. (2007) Application of Shielding Temporary Plugging Technology to Improve the Recognition Ability of Tight Sandstone Gas Logging. Oil Drilling Technology, 29, 113-116.

[4] Xu, L., Li, W.P. Zhu, Q.X., et al. (2000) Study on the Structure of Dynamic Filtration Cake. Fluid Machinery, 28, 26-28.

[5] Jiao, D. and Sharma, M.M. (1992) Damage Due to Formation Static and Dynamic Filtration of Water-Based Muds. SPE23823.

[6] Bailey, L., Meeten, G. and Way, P. (1998) Filter Cake Integrity and Reservoir Damage. SPE39429.

[7] Jason, L., David, B., et al. Correlating Good Well Design Drilling and Cleanup Practices with High Well Productivity. SPE, 65480.

[8] Friehauf, K.E., Suri, A. and Sharma, M.M. (2009) A Simple and Accurate Model for Well Productivity for Hydraulically Fractured Wells. SPE Production \& Operations, 25, 453-460. https://doi.org/10.2118/119264-PA

[9] Jiao, D. (1995) Study on the Formation of Mud Cake during Dynamic Fluid Loss. Drilling Fluid and Completion Fluid, 12, 9-12.

[10] Jiao, D. (1995) Study on Dynamic Mud Cake Formation in Low Permeability Formation. Drilling Fluid and Completion Fluid, 12, 22-24.

[11] Abrams, A. (1975) Mud Design to Minimize Rock Impairment Due to Particle Invasion. SPE5713.

[12] Luo, X.D., et al. (1992) Application Research of Shielded Temporary Plugging Technology in Reservoir Protection. Drilling Fluid and Completion Fluid, 9, 19-27.

[13] Luo, P.Y. (1997) Temporary Plugging Technology. China National Petroleum Company Academy Collection Protection Shield Type Oil Drilling Process, Academician of the Academy of Engineering China - Al. Chinese Encyclopedia Press, Beijing, 68-98.

[14] Aadnoy, B.S., et al. Design of Well Barriers to Combat Circulation Losses. SPE105449-MZ. 
[15] Jiang, H.J. and Yan, J.N. (2000) Experimental Study on the Matching Relationship between the Particle size of Bridging Particles and the Effective Flow Width of Cracks. Drilling fluid and completion, 4, 1-3, 7.

[16] Xu, L., Li, W., Lu, S., et al. (2000) Fractal Study of Filter Cake Structure. Filtration and Separation, 10, 22-25.

[17] Xu, X., Xu, J., Deng, C., et al. (1994) Image Analyzer Test for Cake Structure. China Mining, 3, 60-63.

[18] Zhou, F., Wang, S., Li, J., et al. (2003) Mud Cake Structure Physical Model and Mathematical Model of. Drilling Fluid and Completion Fluid, 20, 4-8.

[19] Ray, M. (1990) Mud Cake Grid Structure of the Theoretical Model of. Oil Drilling Technology, 3, 27-32.

[20] Xin, Y.M. (1992) Determination of the Internal Structure of Filter Cake. Fluid Engineering, 20, 13-19.

[21] Chenevert, M.E. and Huycke, J. (1991) Filter Cake Structure Analysis Using the Scanning Electron Microscope. Society of Petroleum Engineers.

[22] Cheung, T.M., Xu, G., Niu, Y., et al. (1995) Study the Microstructure of Drilling Fluid and Filter Cake with Freeze Drying Technology. Drilling Fluid and Completion Fluid, 12, 1-7.

[23] Xu, X., Deng, C., Luo, Q., et al. (1993) Study on Fractal Structure of Filter Cake. Metal Mine, 9, 42-44.

[24] Hu, X., Rosie and Li, H. (1995) Cake Structure and Fractal Dimension. Mining and Metallurgy, 3, 33-36.

[25] Li, Y., Argillier, J.F., et al. (1995) Correlation between Filter Cake Structure and Filtration Properties of Model Drilling Fluids. SPE International Symposium on Oilfield Chemistry, San Antonio, 14-17 February, SPE-28961-MS.

[26] Ma, X. and Luo, M. (1996) Dynamic Filter Cake on the Microstructure of. Drilling Fluid and Completion Fluid, 13, 19-21.

[27] Liu, P. and Liu, G. (2009) Analysis of the Influence of Particles Properties on Characteristics of Filter Cake. Journal of Filtration \& Separation, 19, 31-33.

[28] Zain, Z.M. and Sharma, M.M. (1999) Cleanup of Wall-Building Filter Cakes. SPE Annual Technical Conference and Exhibition, Houston, 3-6 October 1999, SPE-56635-MS.

[29] Liu, J., Kang, Y. and Liu, D. (2006) Research on the Temporary Shielding Plugging Experiment in Considering Fracture-Pore Reservoir of Fracture Width and Pressure Difference. Drilling \& Production Technology, 29, 97-98, 101.

[30] Ding, Y., Renard, G., et al. (2001) Modeling of Near-Wellbore Damage Removal by Natural Cleanup in Horizontal Open Hole Completed Wells. SPE European Formation Damage Conference, The Hague, 21-22 May 2001, SPE 68951.

[31] Mikhailov, M., Zhu, D. and Hill, A.D. (2008) An Experimental Investigation of Drilling-Fluid Filter-Cake Removal by Acid Jetting. SPE International Symposium and Exhibition on Formation Damage Control, Lafayette, 13-15 February 2008, SPE-112373-MS.

[32] Wang, F., Qiu, Z., Ding, R., et al. (2001) A New Method to Remove Drilling Mud Cake in Fractured Reservoir. Petroleum Drilling Techniques, 29, 29-31.

[33] Nasr-El-Din, H.A., Al-Otaibi, M.B., et al. (2005) Laboratory Studies of In-Situ Generated Acid to Remove Filter Cake in Gas Wells. SPE Annual Technical Conference and Exhibition, Dallas, 9-12 October 2005, SPE-96965-MS.

[34] Al-Otaibi, M.B., Al-Moajil, A.M. and Nasr-El-Din, H.A. (2006) In-Situ Acid System 
to Clean up Drill-In Fluid Damage in High-Temperature Gas Wells. IADC/SPE Asia Pacific Drilling Technology Conference and Exhibition, Bangkok, 13-15 November 2006, SPE-103846-MS.

[35] Nasr-El-Din, H.A., Al-Otaibi, M.B., et al. (2004) An Effective Fluid Formulation to Remove Drilling Fluid Mud Cake in Horizontal and Multi-Lateral Wells. SPE Drilling \& Completion, 22, SPE-87960-PA. 